\section{Case Reports in Neurology}

\title{
In-Hospital Mechanical Thrombectomy: A Case Report
}

\author{
Tsong-Hai Lee \\ Department of Neurology and Stroke Center, Linkou Chang Gung Memorial Hospital and \\ Chang Gung University College of Medicine, Taoyuan, Taiwan
}

\section{Keywords}

In-hospital · Mechanical thrombectomy $\cdot$ Cardioembolic stroke $\cdot$ Atrial fibrillation

\begin{abstract}
We report on a case of a 59-year-old female patient with atrial fibrillation who received edoxaban. She withdrew edoxaban before tooth extraction. She was brought to our emergency department due to acute onset of left-side weakness. Under the impression of acute ischemic stroke, edoxaban was replaced with aspirin. However, the patient suffered from recurrent cerebral embolism with conscious disturbance. Urgent mechanical thrombectomy was performed due to left internal carotid artery occlusion. Remarkable recovery was noted on the second day after thrombectomy. She was discharged with mild neurological deficit. We suggest that early recognition, assessment, and interventional treatment for patients with in-hospital strokes are favorable for stroke outcome.

\section{Introduction}

Non-vitamin K antagonist oral anticoagulant (NOAC) has been proven to be much safer and more effective than warfarin in the prevention of recurrent cerebral embolism due to nonvalvular atrial fibrillation. However, the time when to resume anticoagulant after acute stroke has been debatable. Mechanical thrombectomy has been recognized as an effective treatment 


\section{Case Reports in Neurology}

Case Rep Neurol 2020;12:22-26

\begin{tabular}{l|l}
\hline DOI: 10.1159/000501001 & @ 2020 The Author(s). Published by S. Karger AG, Basel
\end{tabular} www.karger.com/crn

Lee: In-Hospital Mechanical Thrombectomy

in acute ischemic stroke patients with large artery disease since 2015. However, the use of mechanical thrombectomy for in-hospital acute ischemic stroke is rarely encountered, and the adequate procedure is not well established. We reported a case with NOAC who also received mechanical thrombectomy.

\section{Case Report}

A 59-year-old female patient with a history of paroxysmal atrial fibrillation and receiving edoxaban treatment underwent regular follow-up at the cardiovascular clinic. Due to the preparation of tooth extraction, she was advised by local dentist to stop edoxaban for 5-7 days before the procedure. On the 6th day after edoxaban discontinuation, she was found to have left-side weakness and brought to our emergency department. Brain computed tomogram and angiograms showed no intracranial hemorrhage, no large infarction, and no large artery occlusion. The electrocardiogram (EKG) done 9 days before admission and at the emergency department did not show evidence of atrial fibrillation.

Under the impression of acute right hemisphere minor ischemic stroke, she was admitted with aspirin treatment, and the score of National Institutes of Health Stroke Scale (NIHSS) was 2. Rehabilitation was arranged and a dietician was consulted. The follow-up brain magnetic resonance images showed recent cortical small infarcts at the right medial temporal lobe (Fig. 1a). The brain magnetic resonance time-of-flight (Fig. 1b) and carotid duplex ultrasound showed no intracranial and extracranial large artery stenosis/occlusion. Her condition improved remarkably, and she was able to get up from the bed for and walk on the 3rd admission day. Discharge was arranged on the 7th day after admission. Her relatives and friends came to visit her to congratulate her recovery. She was very excited for the discharge and could not fall into sleep on the 6th admission day.

On the morning of the 7th admission day, she was found to have sudden onset of conscious disturbance and severe right-side weakness with NIHSS score of 22. Emergent brain computed tomographic perfusion (Fig. 2a) and angiograms done $30 \mathrm{~min}$ after the episode showed no intracranial hemorrhage and no large infarction, but there was remarkable perfusion defect (time-to-peak, TTP; Fig. 2a, arrows) at the left temporal area and occlusion of the left internal carotid artery at the T zone (Fig. 2b, arrow). EKG showed atrial fibrillation with rapid response. Embolic occlusion due to atrial fibrillation was highly suspected and mechanical thrombectomy was suggested to family.

The patient received mechanical thrombectomy within $150 \mathrm{~min}$ from stroke onset to puncture, and the left internal carotid artery was completely recanalized (Fig. 2c). She gradually regained her consciousness and was able to communicate with others. The follow-up NIHSS score was 4 and brain computed tomogram revealed no large infarction (Fig. 2d, arrows) on the 2 nd day after thrombectomy. She received rehabilitation again and was able to be discharged with a modified Rankin Scale score of 3 on the 8th day after mechanical thrombectomy.

\section{Discussion/Conclusion}

There is always debate about whether antithrombotic agents should be suspended during invasive procedures or not. Continuous antithrombotic treatment carries the risk of

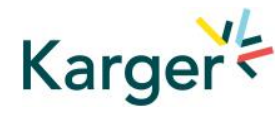




\section{Case Reports in Neurology}

Case Rep Neurol 2020;12:22-26

\begin{tabular}{l|l}
\hline DOI: 10.1159/000501001 & @ 2020 The Author(s). Published by S. Karger AG, Basel
\end{tabular} www.karger.com/crn

Lee: In-Hospital Mechanical Thrombectomy

periprocedural bleeding, while suspension of treatment may increase the thrombotic risk. It is suggested that discontinuation of the long-term use with NOACs can cause a state of hypercoagulation which may lead to severe stroke and poor outcomes [1]. Recent guidelines and review articles have provided recommendations suggesting that for low-risk bleeding procedures, such as tooth extraction, and diagnostic procedures, antithrombotic agents may be continued. However, for high-risk bleeding procedure, such as tooth reconstruction, and major procedures, antithrombotic agents may be temporarily discontinued without the need of bridging therapy in patients with low thrombotic risk but may need bridging therapy in patients with high thrombotic risk [2]. It is advisable that our patient should continue edoxaban treatment under the procedure of tooth extraction.

Whether NOAC, which was used before stroke, should be continued in the acute stage of minor stroke is not concluded mainly due to the fear of increased risk of bleeding. A recent study using a prospective observational inception cohort study (Clinical Relevance Of Microbleeds In Stroke-2) has revealed no significant difference between early and late use of oral anticoagulant after acute ischemic stroke or TIA associated with atrial fibrillation [3]. In patients with atrial fibrillation, it is suggested not to withhold oral anticoagulant following a traumatic injury [4], and restarting oral anticoagulant therapy after a major bleeding event may have a significant reduction in any thromboembolism and all-cause mortality compared to non-restarting [5]. Also, resumption of oral anticoagulant after intracerebral hemorrhage does not increase the risk of recurrent hemorrhage but can reduce the risk of all-cause mortality [6]. However, whether to reach early ( $<2$ weeks) or late ( $>4$ weeks) resumption may need careful risk assessment of hemorrhagic recurrence and thromboembolism.

Urgent treatment is beneficial for mechanical thrombectomy in patients with acute largeartery occlusion. The time duration from stroke onset to groin puncture is reported to independently affect functional outcomes after stroke thrombectomy treatment and should be shortened to obtain the maximum benefit [7]. Little data have discussed the outcomes of mechanical thrombectomy for patients with in-hospital ischemic strokes. Previous study showed that patients with in-hospital stroke who were treated with thrombolytics had higher rates of in-hospital mortality and post-thrombolytic intracerebral hemorrhage [8]. Also, patients with in-hospital stroke may have worse recanalization results and poorer clinical outcomes [9]. However, our case showed that mechanical thrombectomy seems safe for treatment of in-hospital strokes. We suggest that in-hospital stroke should be rescued promptly with adequate procedures. Early recognition, assessment, and interventional treatment for patients with inhospital strokes are favorable for stroke outcome.

\section{Statement of the Ethics}

This research complies with the guidelines for human studies and was conducted ethically in accordance with the World Medical Association Declaration of Helsinki. The patient's guardians gave informed consent to publish the case (including publication of images).

\section{Conflict of Interest Statement}

The authors have no conflicts of interest to declare.

\section{Karger'}




\section{Case Reports in Neurology}

\begin{tabular}{l|l}
\hline Case Rep Neurol 2020;12:22-26 \\
\hline DOI: 10.1159/000501001 & $\begin{array}{l}\text { @ 2020 The Author(s). Published by S. Karger AG, Basel } \\
\text { www.karger.com/crn }\end{array}$ \\
\hline
\end{tabular}

Lee: In-Hospital Mechanical Thrombectomy

\section{Funding Sources}

This case report is sponsored by "Multi-Center Stroke Registry Study in Taiwan - Linkou Chang Gung Memorial Hospital Substudy."

\section{References}

1 Park JH, Han SW, Lee KY, Choi HY, Cheon K, Cho HJ, et al. Impact of Non-vitamin K Antagonist Oral Anticoagulant Withdrawal on Stroke Outcomes. Front Neurol. 2018 Dec;9:1095.

2 Baron TH, Kamath PS, McBane RD. Management of antithrombotic therapy in patients undergoing invasive procedures. N Engl J Med. 2013 May;368(22):2113-24.

3 Wilson D, Ambler G, Banerjee G, Shakeshaft C, Cohen H, Yousry TA, et al.; Clinical relevance of Microbleeds in Stroke (CROMIS-2) collaborators. Early versus late anticoagulation for ischaemic stroke associated with atrial fibrillation: multicentre cohort study. J Neurol Neurosurg Psychiatry. 2019 Mar;90(3):320-5.

4 Staerk L, Fosbøl EL, Lamberts M, Bonde AN, Gadsbøll K, Sindet-Pedersen C, et al. Resumption of oral anticoagulation following traumatic injury and risk of stroke and bleeding in patients with atrial fibrillation: a nationwide cohort study. Eur Heart J. 2018 May;39(19):1698-1705a.

5 Proietti M, Romiti GF, Romanazzi I, Farcomeni A, Staerk L, Nielsen PB, et al. Restarting oral anticoagulant therapy after major bleeding in atrial fibrillation: A systematic review and meta-analysis. Int J Cardiol. 2018 Jun;261:84-91.

6 Li YG, Lip GY. Anticoagulation Resumption After Intracerebral Hemorrhage. Curr Atheroscler Rep. 2018 May;20(7):32.

7 Ota T, Nishiyama Y, Koizumi S, Saito T, Ueda M, Saito N. Impact of onset-to-groin puncture time within three hours on functional outcomes in mechanical thrombectomy for acute large-vessel occlusion. Interv Neuroradiol. 2018 Apr;24(2):162-7.

8 Emiru T, Adil MM, Suri MF, Qureshi AI. Thrombolytic treatment for in-hospital ischemic strokes in United States. J Vasc Interv Neurol. 2014 Dec;7(5):28-34.

9 Mönch S, Lehm M, Maegerlein C, Hedderich D, Berndt M, Boeckh-Behrens T, et al. Worse endovascular mechanical recanalization results for patients with in-hospital onset acute ischemic stroke. J Neurol. 2018 Nov;265(11):2525-30.
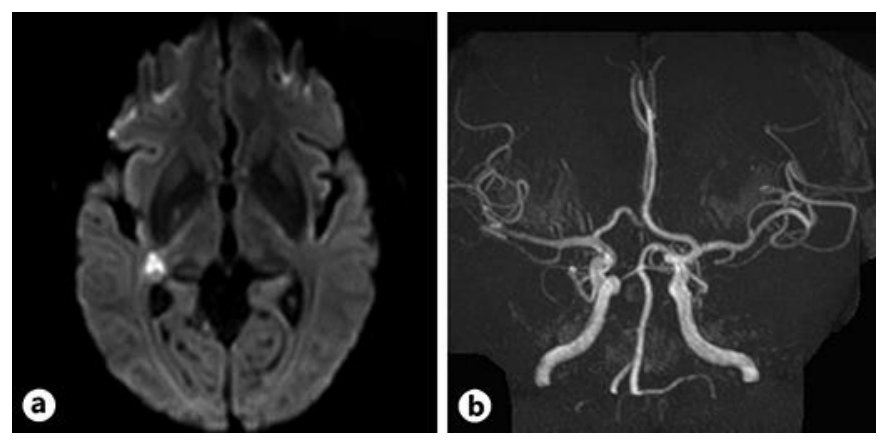

Fig. 1. Follow-up brain magnetic resonance images showed recent cortical small infarcts at the right medial temporal lobe (a). Brain magnetic resonance time-of-flight (b) showed no intracranial large artery stenosis/occlusion. 


\section{Case Reports in Neurology}

\begin{tabular}{l|l}
\hline Case Rep Neurol 2020;12:22-26 \\
\hline DOI: 10.1159/000501001 & $\begin{array}{l}\text { ( ) 2020 The Author(s). Published by S. Karger AG, Basel } \\
\text { www.karger.com/crn }\end{array}$ \\
\hline
\end{tabular}
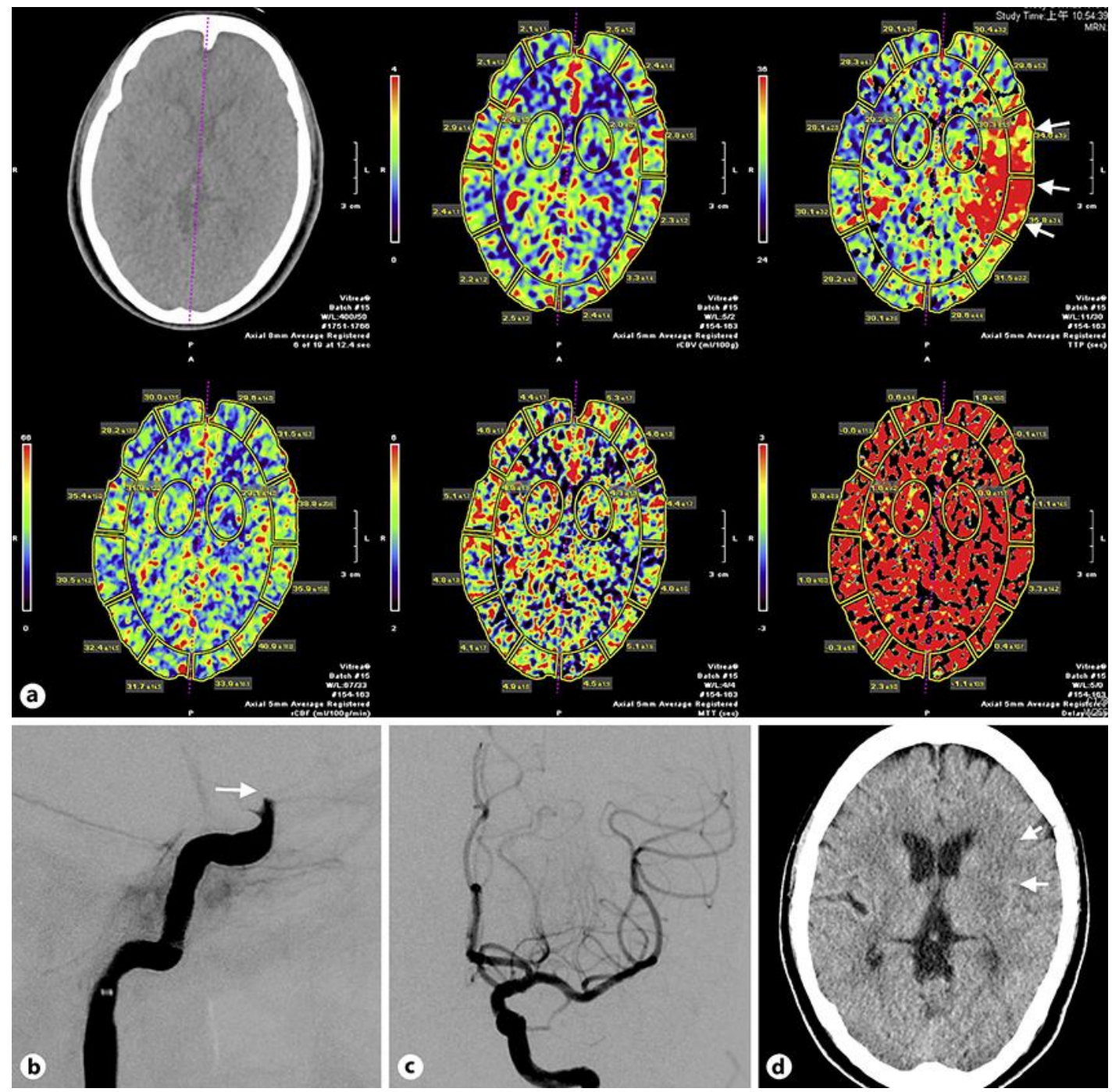

Fig. 2. On the 7th admission day, emergent brain computed tomographic perfusion (a) done 30 min after the episode of right-side weakness showed no intracranial hemorrhage and no large infarction, but there was remarkable perfusion defect on time-to-peak (TTP) image (a, arrows) at the left temporal area, and angiograms revealed occlusion of the left internal carotid artery at the T zone (b, arrow). The patient received mechanical thrombectomy within $150 \mathrm{~min}$ from stroke onset to puncture, and the left internal carotid artery was completely recanalized (c). The follow-up brain computed tomogram revealed no large infarction (d, arrows) on the 2nd day after thrombectomy. 